\title{
Breast Feeding as Analgesia in Neonates: A Randomized Controlled Trial
}

\author{
Singh $R^{1}{ }^{1}$, Simalti $A K^{2}$, Singh $D^{3}$
}

${ }^{1}$ Dr. Rajesh Kumar Singh, MBBS, MD, Assistant Professor, Department of Paediatrics, Command Hospital Central Command, Lucknow, India, ${ }^{2} \mathrm{Dr}$. Ashish Kumar Simalti, MBBS, MD, FNB Paediatric Critical Care, Assistant Professor, Department of Paediatrics, Army Hospital (R\&R), New Delhi, India, ${ }^{3} \mathrm{Dr}$. Daljit Singh, MBBS, MD, DM Neonatology, PMO Central Air Command Allahabad India.

\author{
Address for correspondence: \\ Dr. Ashish Kumar Simalti \\ Assistant Professor, \\ Department of Paediatrics \\ Army Hospital (R\&R), New Delhi, India. \\ Tel No: +919557830552 \\ E-mail: ashishsimalti@gmail.com
}

\author{
Acknowledgements: None \\ Funding: Nil \\ Conflict of Interest: None \\ Permission from IRB: Not Taken as only \\ intervention was breast feeding which is \\ physiological.
}

Ethical dilemmas faced during study: Nil as only intervention was breast feeding which is physiological.

\section{How to cite}

Singh RK, Simalti AK, Singh D. Breast Feeding as Analgesia in Neonates: A Randomized Controlled Trial. J Nepal Paediatr Soc 2016;36(3):238-242.

doi: http://dx.doi.org/10.3126/jnps.v36i3.15688

This work is licensed under a Creative Commons Attribution 3.0 License.

\begin{abstract}
Introduction: Major myth regarding neonatal pain suggests that neonates because of their neurological immaturity do not experience pain. Although exact mechanism is not known, it is proposed that breast feeding through combination of various senses and the closeness of the infant's mother, saturates the senses thus reducing perception of noxious stimuli.The objectives of this study was to investigate the analgesic effect of breastfeeding during blood sampling through heel lance in healthy term neonates. Material and Methods: This was aRandomized controlled trial done in a Tertiary level Neonatal Intensive Care Unit. Sixty healthy term newborns, undergoing heel prick were included in study. Neonates were randomly assigned to two groups: Group I (breastfed) with; Group II (not breast fed). Babies were given heel prick and crying time, Heart rate, $\mathrm{SpO} 2$ and $\mathrm{BP}$ monitored. Changes in various physiological parameters following a heel prick were studied in two groups. Results: Neonates in both groups expressed pain by crying, increase in heart rate, fall in transcutaneous oxygen saturation and rise in blood pressure. Compared to control group, the babies who were breast fed were found to have lesser crying time (40.04 sec and $69.09 \mathrm{sec}$ respectively, $p<0.05$ ) and lesser rise in heart rate (rise of 21.78 and 34.46 bpm respectively, $p<0.03$ ). In the breast fed group there was a trend to a lesser decrease in oxygen saturation and lesser rise in blood pressure though this was not statistically significant. Conclusion: Breast feeding offers a quick and effective means of reducing pain in neonates during routine neonatal procedures.
\end{abstract}

Key words: Breast feeding; Analgesia; Neonates

\section{Introduction}

$\mathrm{N}$ eonatal pain receives limited attention and is treated less vigorously than that of older children and adults. Major myth regarding neonatal pain suggests that neonates because of their neurological immaturity do not experience pain. Studies however strongly dispute this contention ${ }^{1}$. It has been seen that the pain pathways as well as cortical and sub cortical center necessary for pain perception are well developed late in gestation. Neurological systems known to be 
associated with pain transmission and modulation are also intact and functional. Physiological and behavioural responses to pain are well documented ${ }^{2}$. Infants, including newborn babies, experience pain similarly and probably more intensely than older children and adults ${ }^{3}$. Neonates requiring intensive care undergo a number of painful diagnostic \& therapeutic procedures. A wide variety of pharmacological and non pharmacological interventions are available for management of pain in infants. Pharmacological interventions are infrequently employed before performing painful procedures in neonates. This may be due to fear of adverse effects caused by drugs given to neonates. Non pharmacological interventions are more feasible alternatives as they are associated with minimal or no adverse effects. Various studies 4,5,6,7have shown that administration of oral glucose or sucrose raises pain threshold, presumably mediated by endogenous opiates and could be used for this purpose. Although exact mechanism is not known, it is proposed that breast feeding through combination of smell, taste, suck, touch, seeing and hearing, and the closeness of the infant's mother, saturates the senses thus reducing perception of noxious stimuli. This provides an interesting alternative to other nonpharmacological interventions for pain relief in neonates. The aim of this study was to find out analgesic effects of breastfeeding in neonates and the objective were to compare the change in physiological parameters after heel prick between two groups of babies, one being breastfed and other not breastfed and find out if this change was statistically significant.

\section{Material and Methods}

This prospective, randomized, controlled trial involved healthy, full-term, non- asphyxiated neonates up to seven days of life who were scheduled to receive heel sticks to collect blood for obligatory newborn screening at Command Hospital (Air Force) Bangalore.

The study was conducted over 18 months. Sixty term neonates, who were hemodynamically stable and were not receiving oxygen or any analgesia, were included in the study. The neonates whose mothers had received analgesia during labour were excluded from the study. We calculated the sample size to be 30 in each group to achieve a statistically reliable result with a power of $80 \%$ and a $p<0.05$. These neonates were randomized into two groups (30 neonates each) using a system of sealed envelope randomization system. The neonates in test group (Group I) received breastfeeding during heel prick procedure. The neonates in control group (Group II) were not breast fed during heel prick procedure. Participating infants and their mothers were taken to a quiet and warm nursery room for venepuncture. Before skin preparation, a sensor probe of pulse oximeter and blood pressure cuff of noninvasive blood pressure monitor were applied. Baseline heart rate, transcutaneous oxygen saturation and blood pressure were recorded for each neonate before giving the heel prick.

The study protocol was followed only after the neonates achieved calm and drowsy state as checked using Prechtl's observational rating system ${ }^{8}$ : State 1 eyes closed with regular respiration and no movements, state 2 having eyes closed, irregular respiration and small movements and state 3 with eyes open and no movements. The protocol was designed to have a study baseline (2 minutes), intervention (2 minutes) followed by heal prick (10 seconds) and recovery period (10 minutes).

Infants in Group 1 they were breast fed, breast feeding initiated two minutes before the procedure and continuing throughout. The heel prick was performed when the infant had achieved a good attachment at breast as determined by standard signs including baby's mouth being wide open, lower lip turned outward, baby's chin touching mother's breast. In group 2 they were held in their mother's arms without breast feeding, this was done two minutes before the heel prick.

Audio tape recorder was used to record crying. Duration of crying was measured later from recording using a stop watch. Two specially trained observers independently took part in sampling and assessed the recordings. The first gave the prick with autolet, a mechanical device for capillary sampling and second observer recorded the heart rate, transcutaneous oxygen saturation and blood pressure at $0 \mathrm{~min}$ (baseline of the heel prick), $1 \mathrm{~min}, 3 \mathrm{~min}, 5 \mathrm{~min}, 7 \mathrm{~min}$ and 10 min. In addition, the time at which various parameters returned to baseline was also noticed. Duration of cry was measured with a stop watch from first burst of sound until neonate became quiet again. The data thus collected from the study was tabulated and analyzed. A statistical comparison was made using Student'st-test.

Participating mothers signed an informed consent which was approved by the Institutional Review Board allowing their infants to be participants in the study.

\section{Results}

Baseline characteristics: There was no significant difference in sex distribution, median gestational age 
and birth weight between two groups (Table 1). Mean baseline heart rate, transcutaneous oxygen saturation, systolic blood pressure and diastolic blood pressure before the heel prick procedure in the two groups (Table 2). There was no statistically significant difference in baseline variables between the two groups.

Physiological responses: Mean duration of cry period after heel prick has been depicted in table 3 . Mean duration of cry was less in group 1. Difference in mean duration of cry was statistically significant $(p<0.05)$ between two groups (Table 3 ). Both groups showed significant increase in heart rate during the heel prick test. Mean and percentage increase in heart rate over base line heart rate after heel prick was less in group 1. The difference was statistically significant $(p<0.05)$ (Table 3). Both groups showed a non-significant fall in mean transcutaneous oxygen saturation after heel prick (Table 3). Mean fall in transcutaneous oxygen saturation between two groups was statistically non significant (Table 3). Mean rise in systolic blood pressure (SBP) and diastolic blood pressure was less in group ${ }^{1}$. However the difference was statistically non-significant (Table 3).

Table 1: Base line characteristics

\begin{tabular}{cccccccc}
\hline \multirow{2}{*}{ Group } & \multirow{2}{*}{ Breast fed } & \multicolumn{2}{c}{ Sex } & \multicolumn{2}{c}{ Gestational Age (wks) } & \multicolumn{2}{c}{ Birth weight (gm) } \\
\cline { 3 - 8 } & & Male & Female & Median & Range & Mean & Range \\
\hline I & Yes & 14 & 16 & 38 & $37-41$ & 2850 & $2500-3008$ \\
II & No & 15 & 15 & 39 & $37-41$ & 3100 & $2400-3500$ \\
\hline
\end{tabular}

$p$-value- not significant in all parameters

Table 2: Baseline variables

\begin{tabular}{ccccccccc}
\hline Group & \multicolumn{2}{c}{$\begin{array}{c}\text { Baseline heart rate } \\
\text { (beats per } \min \text { ) }\end{array}$} & \multicolumn{2}{c}{ Transcutaneous } & \multicolumn{2}{c}{ oxygen saturation } & & \multicolumn{2}{c}{ SBP $(\mathbf{m g})$} & \multicolumn{2}{c}{$\mathrm{DBP}(\mathbf{m m} \mathrm{Hg})$} \\
\hline & Mean & SD & Mean & SD & Mean & SD & Mean & SD \\
\hline I & 134.9 & 9.85 & 93.42 & 3.32 & 81.40 & 21.28 & 51.75 & 28.93 \\
II & 125.5 & 10.61 & 93.26 & 3.31 & 83.70 & 16.72 & 47.30 & 14.38 \\
\hline
\end{tabular}

SBP systolic blood pressure, DBP diastolic blood pressure, SD standard deviation, $p$-value not significant in all parameters

Table 3: Total duration of cry over 10 min period after heel prick

\begin{tabular}{cccc}
\hline Group & Mean (sec) & SD & $p$-value \\
\hline I & 40.04 & 56.31 & $<0.05$ \\
\hline II & 69.09 & 66.33 & \\
\hline
\end{tabular}

Table 4: Change in heart rate after heel prick

\begin{tabular}{cccc}
\hline Group & Mean (sec) & SD & $p$-value \\
\hline I & 21.78 & 21.74 & $<0.03$ \\
II & 34.46 & 25.10 & \\
\hline
\end{tabular}

Table 5: Fall in transcutaneous oxygen saturation after heel prick

\begin{tabular}{cccc}
\hline Group & Fall in Sao2 (\%) mean & SD & $p$-value \\
\hline I & 1.96 & 2.51 & NS \\
II & 2.00 & 2.56 & \\
\hline
\end{tabular}

NS not significant

Table 6: Mean change in blood pressure of neonates after heel prick test

\begin{tabular}{ccccccc}
\hline Group & SBP $(\mathbf{m m ~ H g})$ & SD & $p$-value & DBP(mm Hg) & SD & $p$-value \\
\hline I & 9.42 & 12.22 & NS & 0.94 & 8.9 & NS \\
\hline II & 14.9 & 14.56 & & 1.86 & 9.5 & \\
\hline
\end{tabular}

SBP systolic blood pressure, DBP diastolic blood pressure, NS not significant 


\section{Discussion}

Pain may be difficult to quantify in neonates, but has far reaching short term as well as long term consequences. The use of breastfeeding as analgesia helps in the avoidance of these effects. The most commonly used parameters include duration of crying and change in heart rate or in blood pressure. Several scales have been advocated to assess pain. These scales are based on behavioural changes (neonatal facial coding system, neonatal infant pain scale) or a combination of physiological and behavioural changes (CRIES- acronym for crying, change in transcutaneous oxygen saturation, heart rate, blood pressure, facial expression and alteration in sleep pattern). However these scales are still not widely used in clinical practice and their value is debated. In this study four easily detectable parameters were used to assess pain. These included duration of crying, changes in heart rate, changes in $\mathrm{SpO} 2$ and changes in blood pressure. These were chosen as they are important parameters in most scales so far suggested and can be easily used in clinical practice. It is not known what components of breastfeeding are most responsible for the analgesic effect. Breast milk contains tryptophan, a precursor of melatonin which increases beta endorphins that may procure pain relief. However, simply administering breast milk to the baby does not provide the same analgesic effect as breastfeeding ${ }^{9}$. Various authors propose that during breastfeeding, the combination of smell, taste, suck, touch, seeing and hearing, and the closeness of the infant's mother, saturates the senses, thereby reducing pain ${ }^{9,10,11}$. In most of the studies done in past, sucrose or glucose have been used as analgesic. However these sweet solutions carry the risk of giving infection to the baby. Breastfeeding is an excellent alternative. The sweet taste/fat content of breast milk acts through release of opioid like substances. Sucking and skin to skin contact also add to analgesia. In a study by Carabjal et al the median pain scores were lowest with breastfed infants ${ }^{12}$. The next-lowest median scores were in infants receiving sucrose and pacifier. Infants held in their mother's arms and those given sterile water had similar median pain scores.

Duration of crying has been found to be sensitive measure of pain. In our study, mean duration of cry after heel prick in control group and breast fed group was $69.09 \mathrm{sec}$ and $40.04 \mathrm{sec}$ respectively. Compared to control group, the breastfed group showed significant $(p<0.05)$ reduction in duration of cry. Breast fed group cried for $44 \%$ lesser time as compared to control group. In fact six of the babies in breast fed group did not cry at all. In a similar study by Gary et al ${ }^{13}$ in term neonates, mean duration of cry was $8.77 \mathrm{sec}$ in neonates who were given breast feeds. It was $72.07 \mathrm{sec}$ in control group. These results are similar to the results obtained in present study. In a study by Blass et al ${ }^{14}$ the babies who were given breast milk cried only for $47 \%$ of time during blood collection as compared to $92 \%$ of time in babies given distilled water. In a study by Upadhyay et $\mathrm{al}^{15}$, mean duration of cry in neonates given expressed milk was 38.5 seconds as compared to babies fed distilled water in whom it was $90 \mathrm{sec}$. Pain scores were lower in breast fed infants in studies by Niranjan $\mathrm{S}$ et al and Uga et al ${ }^{16,17}$. Gary et al showed that kangaroo care reduced crying \& grimacing by $82 \%$ and $65 \%$ respectively ${ }^{18}$. In another study by Codipietro et al, Infant Pain Profile scores were lower in the breastfeeding group than in the sucrose solution group ${ }^{19}$.

In our study, both groups showed significant increase in heart rate from baseline during heel prick procedure. There was rise of 21.78 beats per min in Group 1 and 34.46 beats per min in Group II. The difference was statistically significant. In breast fed babies, rise in heart rate was $37 \%$ lesser as compared to control group. In a study by Gray et $\mathrm{al}^{10}$ breast fed babies had lesser increase in heart rate ( 6 beats per min) when compared to controls (29 beats per min in babies swaddled in crib). This difference was significant and similar to present study. The study by Weissman et al had similar results20. One major limitation of this study is relying on few parameters to assess pain, which are not really gold slandered. Some of these parameters may get affected by effort of breastfeeding or distraction provided by breast feeding. However these parameters were used because of there being non-invasive in nature besides ease of recording, repeatability and objectivity to reduce inter or intra observer variation.

\section{Conclusion}

The results of our study establish the role of breast feeding as an analgesic during routine painful procedures in neonates. Benefits of breastfeeding for both mother and child are well established. Our study highlights yet another advantage of breast feeding.

Recommendation:We suggest that this physiological measure be used universally whenever a healthy neonates needs to receive a painful stimulus like blood sampling. 


\section{References}

1. Anand KJS. Corr DB. The neuroanatomy, neurophysiology and neuroanatomy of pain, stress and analgesia in newborns and children. Ped Clin N Am 1989;36:795-818.

2. Rushforth JA, Levene MI. Behaviour response to pain in healthy neonate. Arch Dis Child 1994;70:F 174-176.

3. Mathew PJ, Mathew JL. Assessment and management of pain in infants. Postgrad Med J 2003;79:438-443.

4. Blass EM, Hoffmeyer LB. Sucrose as an analgesic foe newborn infants. Pediatrics 1991;87:215-218.

5. Haouari N, Wood C, Griffiths G, Levene M. The analgesic effect of sucrose in full term infants: A randomized controlled trial. BMJ 1995;310:1498-1500.

6. Rushforth JA, Levene MI. Effect of sucrose on crying response to heel stab. Arch Dis Child 1993;69:388389.

7. Schillin J. Analgesic effect of expressed breast milk in procedural pain in neonates. Acta Paediatr 2004;93:453-55.

8. Prechtl HFR. The behavioural states of newborn infant (a review). Brain Res 1974;76(2):185-212.

9. Osinaike BB, Oyedeji AO, Adeoye OT, Dairo $M D$, Aderinto DA. Effect of breastfeeding during venepuncture in neonates. Ann Trop Paediatr2007;27:201-205.

10. Holsti L, Oberlander TF, Brant R. Does breastfeeding reduce acute procedural pain in preterm infants in the neonatal intensive care unit? A randomised clinical trial. Pain2011;152:2575-581.

11. Phillips RM, Chantry CJ, Gallagher MP. Analgesic effects of breast-feeding or pacifier use with maternal holding in term infants. Ambul Pediatr2005;5:359-64.
12. Carbajal R, Veerapen $S$, Couderc $S$, Jugie M, Ville $Y$ Analgesic effect of breastfeeding in term neonates: randomized controlled trial. J Pediatr 2003;143:137.

13. Gray L, Miller BA, Phillip BL, Blass EM. Breast feeding is analgesic in healthy newborns. Pediatrics 2002;109:590-93.

14. Blass EM. Milk induced hypoalgesia in Human Newborns. Pediatrics 1997;99:825-29.

15. Upadhyay A, Aggrawal R, Narayanan S, Joshi M, Paul VK, Deorari AK. Analgesic effect of expressed breast milk in procedural pain in term neonates: a randomized placebo-controlled, double blind trial. Acta Paedr 2004;93(4):518-22.

16. Niranjan S, Gandhi S. Analgesic effects of breastfeeding on heel lancing. Indian Pediatr 2005;42:730-732.

17. Uga E, Candriella M, Perino A, Alloni V, Angilella G, Trada M, Ziliotto AM, Rossi MB, Tozzini D Tripaldi C, Vaglio M, Grossi L, Allen M, Provera S. Heel lance in newborn during breastfeeding: an evaluation of analgesic effect of this procedure. Italian $J$ Pediatr 2008;34:3

18. Gray L, Watt L, Blass EM. Skin-to-Skin Contact Is Analgesic in Healthy Newborns. Pediatrics 2000;05:14

19. Codipietro L, Ceccarelli M, Ponzone A. Breastfeeding or Oral Sucrose Solution in Term Neonates Receiving Heel Lance: A Randomized, Controlled Trial. Pediatrics 2008;122:716-21.

20. Weissman A, Aranovitch M, Blazer S, Zimmer EZ. Heel-Lancing in Newborns: Behavioral and Spectral Analysis Assessment of Pain Control Methods. Pediatrics 2009;24(5):921-26. 